\title{
THE EFFECT OF NOREPINEPHRINE ON CARDIAC OUTPUT, ARTERIAL BLOOD PRESSURE, AND HEART RATE IN DOGS TREATED WITH CHLOROTHIAZIDE * $\dagger$
}

\author{
By JOHN W. ECKSTEIN, $¥$ FRANCOIS M. ABBOUD § ANd SANTIAGO A. PEREDA \| \\ (From the Hemodynamic Laboratory, Cardiovascular Research Laboratories, Department of \\ Internal Medicine, State University of Iowa College of Medicine, Iowa City, \\ Iowa)
}

(Submitted for publication December 11, 1961; accepted April 5, 1962)

Forearm blood flow in normal human subjects was found to decrease progressively during intravenous infusions of norepinephrine as the rate of infusion increased (2). After 1 week of treatment with chlorothiazide, the same subjects responded to the same doses of norepinephrine with progressive increases in flow. This reversal of the response might be interpreted as redistribution of blood flow into the extremity because of relatively greater vasoconstriction in other vascular beds. It also could be the result of increased cardiac output with the proportion of blood flow to the various vascular beds remaining the same. The latter hypothesis seemed more attractive.

The experiments to be reported here were done on intact dogs to see if treatment with chlorothiazide alters hemodynamic responses to norepinephrine.

\section{METHODS AND PROCEDURE}

The experiments were done on 12 male, mongrel dogs weighing 10 to $15 \mathrm{~kg}$. Six were given daily intravenous injections of chlorothiazide, $25 \mathrm{mg}$ per $\mathrm{kg}$ for 7 days. Six were untreated. All were given water ad libitum and the same diet (based on body weight) of canned commercial dog food for 7 days before the acute experiments were carried out. A program was arranged so

* Submitted in honor of Chester S. Keefer, M.D., and the Golden Anniversary of the Evans Memorial Department of Clinical Research, Boston, Mass.

$\dagger$ Presented at the Thirty-fourth Scientific Sessions of the American Heart Association, Miami Beach, Fla., October 20, 1961 (1). Supported by Grant H-2644 from the National Heart Institute, Bethesda, Md., and aided by grants from the Iowa and American Heart Associations.

$\ddagger$ Established Investigator of the American Heart Association.

$\S$ Advanced Research Fellow of the American Heart Association.

|| Postgraduate Trainee under Grant HTS-5367 from the National Heart Institute. that treated and untreated animals were available for study on the morning of the eighth day.

The dogs were lightly anesthetized with $10 \mathrm{mg}$ thiopental sodium per $\mathrm{kg}$ and treated with $0.3 \mathrm{mg}$ decamethonium bromide per $\mathrm{kg}$. A cuffed endotracheal tube was inserted immediately, and intermittent positive pressure breathing was instituted with a Harvard respiratory pump. Two cardiac catheters were introduced through the external jugular vein so that their tips lay in the main pulmonary artery and right atrium. Needles were inserted into the left carotid and femoral arteries and into a femoral vein. Pressures were recorded from the femoral artery and right atrium with Statham strain gauges. Drugs were given through the needle in the femoral vein. The catheter in the pulmonary artery was filled with indocyanine green dye and connected through a three-way stopcock to a dye reservoir and injection system. The needle in the carotid artery was connected through small-bore, nylon tubing to the cuvet of a Gilford densitometer. Dye curves were obtained by drawing blood through the densitometer with a constant speed pump after injections into the pulmonary artery. Endexpiratory $\mathrm{CO}_{2}$ concentration was monitored with a Spinco $\mathrm{CO}_{2}$ analyzer. Dye curves, $\mathrm{CO}_{2}$ concentration, and blood pressure were recorded with a Sanborn direct-writing oscillograph.

Ventilation was adjusted by manipulating the controls on the respiratory pump so that end-expiratory $\mathrm{CO}_{2}$ concentration, after it became stable, was about 4 per cent. The rate and depth of breathing were not changed after this initial adjustment. Repeated doses of $0.075 \mathrm{mg}$ decamethonium per $\mathrm{kg}$ were given at 20 -minute intervals to maintain skeletal muscle relaxation. After the animal was prepared, 15 to 20 minutes were allowed for blood pressure and heart rate to become stable. Then $l$-norepinephrine bitartrate was infused intravenously at rates of $0.1,0.2$, and $0.4 \mu \mathrm{g}$ of norepinephrine base per $\mathrm{kg}$ per minute. Each dose was repeated once in each animal. The doses were given in random order both in the untreated and treated groups, using the same $6 \times 6$ Latin square (3). Observations on cardiac output, heart rate, and blood pressures were made immediately before and at the end of 2.5 minutes of norepinephrine infusion. Exactly 10 minutes were allowed between infusions. Electrically integrated mean right atrial pressures were recorded throughout the inscription of each dye curve. 
Phasic systemic arterial pressure was registered as the curve was obtained so that heart rate could be counted. Fifty $\mathrm{ml}$ of blood was taken at the beginning of the experiment for calibration of the densitometer. The blood taken during each dye curve was returned to the dog immediately after the inscription of the curve by reversing the motor on the withdrawal pump. Appropriate precautions (4) were taken to avoid loss of color of the indicator and excessive accumulation of background dye in the blood.

Cardiac output was calculated from the dye curves using the Stewart-Hamilton equations (5). Peripheral resistance was calculated by dividing the difference between mean arterial pressure and mean right atrial pressure (in millimeters of $\mathrm{Hg}$ ) by cardiac output (in $\mathrm{L}$ per minute); it is expressed in arbitrary units.

Dose-response regressions were computed according to methods described by Snedecor (6). A response to a given dose of norepinephrine was calculated as the difference between the observation made immediately before each infusion of norepinephrine and at the end of 2.5 minutes of infusion. Parallel line bioassays were carried out whenever the dose-response regressions for both groups of dogs were linear and parallel and satisfied the other requirements for such assays (7). These computations were done by regarding norepinephrine in untreated animals as the standard preparation and norepinephrine in treated animals as the test preparation. Since the absolute doses of norepinephrine were the same in both groups, the calculated potency ratio and its confidence limits serve as a statistical expression showing a difference between treated and untreated animals. Whenever the regressions did not meet the requirements for a parallel line assay, the two groups were compared by considering the significance of the regression coefficients and the mean values and confidence limits for the responses to all doses.

\section{RESULTS}

The dose-response curves for heart rate, mean blood pressure, cardiac output, and peripheral resistance are plotted in Figure 1. A statistical summary of the data relating to these functions as well as to the stroke volume is given in Table I.

The dose-response regressions and the means of all the responses show very well the differences in the effects of norepinephrine on cardiac output and peripheral resistance in the two groups of animals. In untreated dogs the changes in output were small, statistically insignificant, and unrelated to the dose of norepinephrine (Table I). In treated dogs output increased significantly and the increases were linearly related to the dose. Peripheral resistance increased progressively with increasing doses of norepinephrine in untreated animals, whereas in treated dogs the increases were
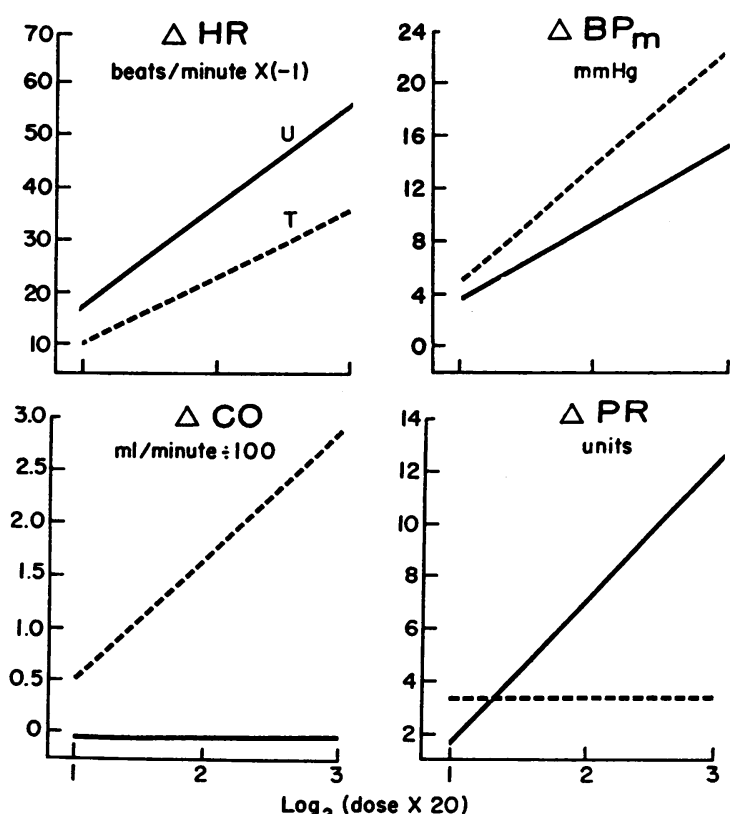

Fig. 1. Dose-REsPonse CURVES FOR HEART RATE $\left(\triangle\right.$ HR), MEAN ARTERIAL BLOOD PRESSURE $\left(\Delta \mathrm{BP}_{\mathrm{m}}\right)$, CARDIAC OUTPUT ( $\triangle \mathrm{CO})$, AND PERIPHERAL RESISTANCE $(\Delta \mathrm{PR})$. Where the regression coefficient was not significant (Table I), a line was drawn parallel to the abscissa through the mean value for the response. $U$ refers to data obtained from dogs which were not treated with chlorothiazide. $T$ refers to data obtained from treated dogs. The regression equation is: $y=\bar{y}+b$ $(x-\bar{x})$. The computations were done after transforming the dose of norepinephrine to $\log _{2}$ (actual dose $\times 20$ ). Other transformations are shown on the ordinates.

smaller, statistically insignificant, and unrelated to the dose.

The effects of norepinephrine on heart rate, mean blood pressure, and stroke volume could be compared by means of the bioassay. Analysis of variance revealed that for these parameters the data fulfilled the requirements outlined by Finney (7). It was found (Figure 2) that $1 \mathrm{U}$ of norepinephrine was required to produce the same decrease in heart rate in treated dogs that $0.62 \mathrm{U}$ produced in untreated animals. More norepinephrine, however, was required to produce the same increases in mean blood pressure and stroke volume in untreated dogs. In other words, a given dose of norepinephrine was less effective in reducing heart rate in treated animals, even though the same dose caused greater increases in blood pressure and stroke volume.

The experiments were not designed to com- 
TABLE I

Parameters of the regression equations for responses to norepinephrine in untreated dogs $(U)$ and in those treated with chlorothiazide $(T)^{*}$

\begin{tabular}{|c|c|c|c|c|c|c|c|}
\hline \multirow{2}{*}{$\frac{\text { Item }}{\text { Heart rate }(\text { beats } / \text { min })^{-1}}$} & \multirow{2}{*}{$\frac{\text { Group }}{\underset{\mathrm{T}}{\mathrm{U}}}$} & \multirow{2}{*}{$\begin{array}{c}b \\
18.67 \\
12.42\end{array}$} & \multicolumn{2}{|c|}{ Limits } & \multirow{2}{*}{$\begin{array}{c}\bar{y} \\
36.56 \\
26.17\end{array}$} & \multicolumn{2}{|c|}{ Limits } \\
\hline & & & $\begin{array}{l}7.55 \\
4.69\end{array}$ & $\begin{array}{l}29.79 \\
20.15\end{array}$ & & $\begin{array}{l}27.47 \\
19.86\end{array}$ & $\begin{array}{l}45.65 \\
32.48\end{array}$ \\
\hline Mean blood pressure $(m m \mathrm{Hg})$ & $\begin{array}{l}\mathrm{U} \\
\mathrm{T}\end{array}$ & $\begin{array}{l}5.50 \\
8.68\end{array}$ & $\begin{array}{l}2.66 \\
5.09\end{array}$ & $\begin{array}{r}8.34 \\
12.27\end{array}$ & $\begin{array}{r}9.30 \\
13.67\end{array}$ & $\begin{array}{l}7.08 \\
4.33\end{array}$ & $\begin{array}{l}11.52 \\
23.01\end{array}$ \\
\hline Cardiac output $(\mathrm{ml} / \mathrm{min}) \times 10^{-2}$ & $\underset{T}{\mathrm{U}}$ & $\begin{array}{r}-0.38 \\
1.20\end{array}$ & $\begin{array}{r}-0.85 \\
0.02\end{array}$ & $\begin{array}{l}0.09 \\
2.38\end{array}$ & $\begin{array}{r}-0.06 \\
1.70\end{array}$ & $\begin{array}{r}-0.45 \\
0.73\end{array}$ & $\begin{array}{l}0.33 \\
2.67\end{array}$ \\
\hline Peripheral resistance (units) & $\underset{T}{\mathrm{U}}$ & $\begin{array}{r}5.50 \\
-0.08\end{array}$ & $\begin{array}{r}1.20 \\
-4.36\end{array}$ & $\begin{array}{l}9.80 \\
4.20\end{array}$ & $\begin{array}{l}6.94 \\
3.25\end{array}$ & $\begin{array}{r}3.43 \\
-0.26\end{array}$ & $\begin{array}{r}10.45 \\
6.76\end{array}$ \\
\hline Stroke volume $(m l \times 10)$ & $\underset{T}{\mathrm{U}}$ & $\begin{array}{l}14.75 \\
31.00\end{array}$ & $\begin{array}{r}5.33 \\
16.02\end{array}$ & $\begin{array}{l}24.17 \\
45.98\end{array}$ & $\begin{array}{l}26.94 \\
49.08\end{array}$ & $\begin{array}{l}19.25 \\
36.86\end{array}$ & $\begin{array}{l}34.63 \\
61.30\end{array}$ \\
\hline
\end{tabular}

* See legend for Figure 1. The limits include the upper and lower values for the $95 \%$ confidence intervals. A response to norepinephrine, $\bar{y}$, or the slope, $b$, of a regression equation is considered to be statistically significant if zero is not included within the $95 \%$ confidence interval.

pare the effects of chlorothiazide on resting hemodynamic parameters. There were only 6 "resting" observations (observations made before any norepinephrine was given) in each group. The mean
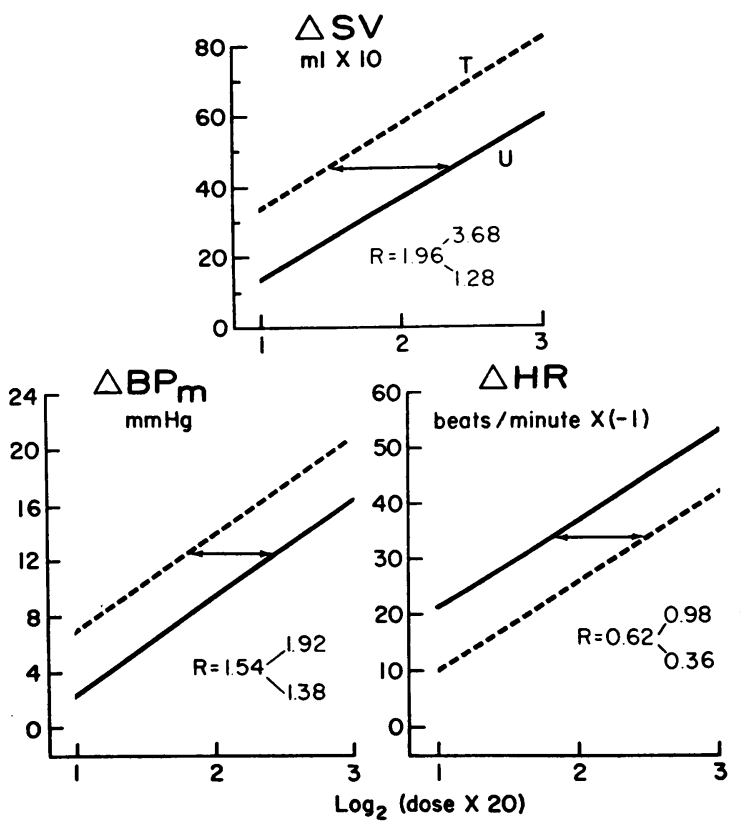

Fig. 2. COMPARISON OF EFFECTS OF NOREPINEPHRINE ON STROKE VOLUME ( $\Delta$ SV), MEAN ARTERIAL BLOOD PRESSURE $\left(\Delta \mathrm{BP}_{\mathrm{m}}\right)$, AND HEART RATE $(\Delta \mathrm{HR})$ IN UNTREATED DOGS AND IN DOGS TREATED WITH CHLOROTHIAZIDE. The comparison was made by using the technique of a parallel line assay (see text). This was done by regarding norepinephrine in treated animals as the test preparation and norepinephrine in untreated animals as the standard preparation. $R$ refers to the potency ratio and its 95 per cent confidence limits. The other abbreviations and transformations are described in the legend for Figure 1. values and the upper and lower limits for the 95 per cent confidence intervals for these items are included in Table II to show the distribution of the observations. The confidence limits suggest that there is no significant difference between the groups with respect to resting cardiac output, mean arterial pressure, peripheral resistance, heart rate, and stroke volume. Caution should be employed, however, in extending this interpretation beyond the limits of the present experiments because of the limited number of observations and the variability among dogs.

Table III contains mean values and confidence limits for all the observations made immediately before each norepinephrine infusion. There are 36 observations in each group. Of these, six are the resting observations in Table II. The remain-

TABLE II

Resting hemodynamic observations in treated and untreated dogs *

\begin{tabular}{lcrrr}
\hline \multicolumn{1}{c}{ Item } & Group & \multicolumn{1}{c}{$\bar{y}$} & \multicolumn{2}{c}{ Limits } \\
\hline Heart rate (beats $/$ & $\mathrm{U}$ & 177.0 & 137.1 & 216.9 \\
min) & $\mathrm{T}$ & 133.0 & 94.4 & 171.6 \\
Mean blood pressure & $\mathrm{U}$ & 123.2 & 104.2 & 142.2 \\
$\quad$ (mm Hg) & $\mathrm{T}$ & 144.1 & 100.9 & 144.1 \\
Cardiac output $(\mathrm{ml} /$ & $\mathrm{U}$ & 16.8 & 11.4 & 22.2 \\
min) X 10 & $\mathrm{T}$ & 21.4 & 12.9 & 29.9 \\
Stroke volume & $\mathrm{U}$ & 102.7 & 69.3 & 136.1 \\
$\quad$ (ml X 10) & $\mathrm{T}$ & 158.3 & 129.8 & 186.8 \\
Peripheral resistance & $\mathrm{U}$ & 82.0 & 46.8 & 117.2 \\
(units) & $\mathrm{T}$ & 64.0 & 36.2 & 91.8 \\
\hline
\end{tabular}

* Observations before any norepinephrine was given The number of observations in each group is 6 . See footnotes to Table I and the legend for Figure 1 . 
TABLE III

Initial hemodyamic observations in treated and untreated dogs *

\begin{tabular}{|c|c|c|c|c|}
\hline Item & Group & $y$ & \multicolumn{2}{|c|}{ Limits } \\
\hline $\begin{array}{l}\text { Heart rate (beats/ } \\
\quad \text { min) }\end{array}$ & $\stackrel{\mathrm{U}}{\mathrm{T}}$ & $\begin{array}{l}173.1 \\
145.0\end{array}$ & $\begin{array}{l}156.5 \\
135.1\end{array}$ & $\begin{array}{l}189.7 \\
154.9\end{array}$ \\
\hline $\begin{array}{l}\text { Mean blood pressure } \\
\quad(m m H g)\end{array}$ & $\begin{array}{l}\mathrm{U} \\
\mathrm{T}\end{array}$ & $\begin{array}{l}116.9 \\
117.2\end{array}$ & $\begin{array}{l}111.0 \\
111.5\end{array}$ & $\begin{array}{l}122.8 \\
122.9\end{array}$ \\
\hline $\begin{array}{l}\text { Cardiac output }(\mathrm{ml} / \\
\quad \text { min }) \times 10^{-2}\end{array}$ & $\stackrel{\mathrm{U}}{\mathrm{T}}$ & $\begin{array}{l}16.7 \\
21.3\end{array}$ & $\begin{array}{l}15.3 \\
18.7\end{array}$ & $\begin{array}{l}18.1 \\
23.9\end{array}$ \\
\hline $\begin{array}{l}\text { Stroke volume } \\
\quad(m l \times 10)\end{array}$ & $\stackrel{\mathrm{U}}{\mathrm{T}}$ & $\begin{array}{l}106.4 \\
148.9\end{array}$ & $\begin{array}{r}91.2 \\
137.3\end{array}$ & $\begin{array}{l}121.6 \\
160.5\end{array}$ \\
\hline $\begin{array}{l}\text { Peripheral resistance } \\
\text { (units) }\end{array}$ & $\mathrm{U}$ & $\begin{array}{l}73.9 \\
59.0\end{array}$ & $\begin{array}{l}65.9 \\
52.7\end{array}$ & $\begin{array}{l}81.3 \\
65.3\end{array}$ \\
\hline
\end{tabular}

* Observations made immediately before norepinephrine infusions. The number of observations in each group is 36. See footnotes to Table I and the legend for Figure 1.

ing 30 were made 10 minutes after a previous infusion. These might be called "recovery" observations. The responses described in Table I were calculated from these 30 recovery observations and the six resting observations. The data in Table III, therefore, show the distribution of the 36 "initial" observations from which the responses were calculated.

\section{DISCUSSION}

In these experiments there was no increase in cardiac output in response to norepinephrine in dogs which had not received chlorothiazide. This observation is in agreement with the generally accepted view that norepinephrine does not increase output in intact dogs or normal men (8-13). Increases in cardiac output with norepinephrine have been reported in men and dogs, however, when the regulatory reflexes mediated over the vagi are inhibited $(9,14)$. In our experiments cardiac output did increase with increasing doses of norepinephrine in treated animals, suggesting that the sensitivity of these cardioregulatory reflexes may have been altered by the chlorothiazide.

The carotid sinus and aortic arch baroreceptors are sensitive to changes in stroke volume as well as to changes in mean blood pressure (15). Under ordinary circumstances the increases in blood pressure caused by norepinephrine would stimulate these baroreceptors and cause reflex bradycardia. In our experiments on untreated animals, norepinephrine caused appreciable reductions in heart rate. After treatment with chlorothiazide, the same doses of norepinephrine caused significantly smaller reductions in heart rate, even in the presence of greater increases in mean blood pressure and stroke volume at each dose. Thus, for greater baroreceptor stimulation there was a smaller bradycrotic response. It might be argued that this is not really a smaller response, since it originated from a lower resting heart rate (Table III). In this connection, it should be pointed out that the percentage change in heart rate (as well as the absolute change) also was smaller in treated animals.

Norepinephrine and sympathetic stimulation increase the work output of the heart (16-18), whereas stimuli mediated over the vagi decrease it by decreasing the force of atrial contraction (19). If the regulatory reflexes are intact, therefore, one would expect the positive inotropic effect of norepinephrine on the heart to be modified by the negative inotropic effect of the sympathetic inhibition and by the vagal discharge triggered by the rise in arterial pressure. Stroke work may be expressed roughly as the product of stroke volume and mean arterial pressure. We did not include this calculation, but it is obvious from inspection of the data in Table I that there was a far greater increase in stroke work in response to norepinephrine in animals treated with chlorothiazide. The increase in cardiac output, the greater increase in stroke work, and the smaller decrease in heart rate with norepinephrine in treated animals lead us to the hypothesis that chlorothiazide decreases the sensitivity of the regulatory reflexes which originate in the arterial baroreceptors.

Of particular interest are the mechanisms responsible for the increases in blood pressure in the two groups of dogs during infusion of norepinephrine. In untreated animals norepinephrine caused blood pressure to increase only because of active vasoconstriction, since there was no increase in cardiac output. In treated animals the increases in pressure may be attributed chiefly to increases in cardiac output, since there was little increase in peripheral resistance. The data from these experiments are in agreement with previously reported data from blood pressure and blood flow studies which demonstrated that chlorothiazide reduced the responsiveness of human forearm blood vessels to the constrictor effects of norepinephrine 
(2). The greater blood pressure responses to a given dose of norepinephrine in our treated dogs would appear to be in disagreement with the reduced blood pressure responses to norepinephrine observed in normotensive and hypertensive human subjects after treatment with chlorothiazide $(20-23)$. In our minds there is no essential disagreement. The general interpretation drawn from these decreased pressor responses in humans is that vascular responsiveness to the vasoconstrictor effect of norepinephrine is reduced by chlorothiazide. We draw a similar interpretation from the results of these experiments in dogs in which both pressure and flow were measured in response to norepinephrine.

To our knowledge there are no other measurements of cardiac output during infusions of norepinephrine in human subjects or experimental animals treated with chlorothiazide. It is interesting to note, however, that the cardiac output increased appreciably in response to exercise in two normal subjects after they had received chlorothiazide (24).

The work of several investigators suggests that resting cardiac output in hypertensive humans is unchanged or reduced by treatment with chlorothiazide (24-27). To our knowledge there are no measurements of resting cardiac output in dogs before and after administration of chlorothiazide. The mean values and the confidence limits for resting cardiac output in Table II suggest that there is no significant difference between treated and untreated dogs. Caution should be employed in considering this finding in connection with the reported observations on resting output in hypertensive human subjects (24-28). The experiments are not comparable, and ours were not designed to show differences in resting hemodynamic parameters.

The data in Table III suggest that there are significant differences between initial observations in treated and untreated dogs with respect to heart rate, cardiac output, peripheral resistance, and stroke volume. Again, caution should be employed in extending these interpretations beyond the context of the present experiments. Of the 36 initial observations in each group, 30 were made 10 minutes after an infusion of norepinephrine was discontinued. It was apparent during several of the experiments that some norepinephrine effect remained at the end of 10 minutes. If this were appreciable, the observations made immediately before each infusion in treated animals would represent the results of an interaction between the residual effects of norepinephrine and the effects of chlorothiazide, and the differences would convey the same sort of information as the responses to the infusions. This "carry-over" effect of norepinephrine was present in both groups of dogs, and it would tend to reduce rather than to exaggerate the calculated responses. This would serve to minimize the apparent differences between the two groups of animals. For this reason a carryover effect, even if it were significant, would not alter the conclusions. Comparison of the data of Table III with those in Table I reveals that the responses in cardiac output to norepinephrine were greater in treated dogs even though initial outputs were higher, and that responses in peripheral resistance were less in treated animals even though initial values were lower. Similarly, the responses of stroke volume to norepinephrine were greater in treated dogs even though the initial values for stroke volume were higher.

The relatively high initial heart rate in untreated dogs (Table III) must be ascribed to two animals in the untreated group which had very rapid rates during rest. The changes in rate in these two cases were proportional to the changes seen with norepinephrine in other dogs. This is apparent from the significance of the regression coefficient for the responses in heart rate (Table I). Since no other explanation is available, the high initial values must be ascribed to variability among animals. It should be mentioned, however, that the heart rate of dogs given barbiturates may be quite variable and that unusually high rates are not uncommon.

\section{SUM MARY}

Hemodynamic responses to intravenous infusions of norepinephrine were studied in control dogs and in dogs treated with chlorothiazide. In these experiments chlorothiazide reduced the responses of peripheral blood vessels to the vasoconstrictor effects of norepinephrine. It also modified the effect of norepinephrine on heart rate and cardiac output. The data suggest that chlorothiazide alters the sensitivity of cardioregulatory reflexes. 


\section{REFERENCES}

1. Eckstein, J. W., Pereda, S. A., Abboud, F. M., and Wendling, M. G. Effect of chlorothiazide on cardiac output responses to norepinephrine (Abstract). Circulation 1961, 24, 923.

2. Feisal, K. A., Eckstein, J. W., Horsley, A. W., and Keasling, H. H. Effects of chlorothiazide on forearm vascular responses to norepinephrine. J. appl. Physiol. 1961, 16, 549.

3. Fisher, R. A. The Design of Experiments, 7 th ed. New York, Hafner Publishing Company, 1960, p. 91.

4. Eckstein, J. W., and Horsley, A. W. The effects of reduced cardiac sympathetic tone on myocardial function. J. clin. Invest. 1961, 40, 555.

5. Hamilton, W. F., Moore, J. W., Kinsman, J. M., and Spurling, R. G. Studies on the circulation. IV. Further analysis of the injection method, and of changes in hemodynamics under physiological and pathological conditions. Amer. J. Physiol. 1932, 99, 534.

6. Snedecor, G. W. Statistical Methods Applied to Experiments in Agriculture and Biology, 5th ed. Ames, Iowa, State College Press, 1956, pp. 122 159.

7. Finney, D. J. Statistical Method in Biological Assay. London, Charles Griffin, 1952, pp. 98-163.

8. Shadle, O. W., Moore, J. C., and Billig, D. M. Effect of $l$-arterenol infusion on "central blood volume" in the dog. Circulat. Res. 1955, 3, 385.

9. Collier, H. D., Meyers, F. H., and Schmitt, G. H. Hemodynamic effects of infusions of epinephrine and arterenol in normal and shocked dogs. Amer. J. Physiol. 1957, 189, 224.

10. Goldenberg, M., Pines, K. L., Baldwin, E. de F., Greene, D. G., and Roh, C. E. The hemodynamic responses of man to nor-epinephrine and epinephrine and its relation to the problem of hypertension. Amer. J. Med. 1948, 5, 792.

11. Barcroft, H., and Starr, I. Comparison of the actions of adrenaline and noradrenaline on the cardiac output in man. Clin. Sci. 1951, 10, 295.

12. Fowler, N. O., Westcott, R. N., Scott, R. C., and McGuire, J. The effect of nor-epinephrine upon pulmonary arteriolar resistance in man. J. clin. Invest. 1951, 30, 517.

13. Tuckman, J., and Finnerty, F. A., Jr. Cardiac index during intravenous levarterenol infusion in man. Circulat. Res. 1959, 7, 988.

14. Wilber, J. A., and Brust, A. A. The circulatory and metabolic effects in man of histamine, Mecholy1 ${ }^{\circledR}$, tetraethylammonium and atropine in the presence of circulating epinephrine and nor-epinephrine. J. clin. Invest. 1958, 37, 476.

15. Heymans, C., and Neil, E. Reflexogenic Areas of the Cardiovascular System. London, J. \& A. Churchill, 1959, pp. 72-82.

16. Shipley, R. E., and Gregg, D. E. The cardiac response to stimulation of the stellate ganglia and cardiac nerves. Amer. J. Physiol. 1945, 143, 396.

17. Anzola, J., and Rushmer, R. F. Cardiac responses to sympathetic stimulation. Circulat. Res. 1956, 4, 302.

18. Sarnoff, S. J. Certain aspects of the role of catecholamines in circulatory regulation. Amer. J. Cardiol. 1960, 5, 579.

19. Sarnoff, S. J., Gilmore, J. P., Brockman, S. K., Mitchell, J. H., and Linden, R. J. Regulation of ventricular contraction by the carotid sinus : Its effect on atrial and ventricular dynamics. Circulat. Res. 1960, 8, 1123.

20. Merrill, J. P., Guinand-Baldo, A., and Giordano, C. The effect of chlorothiazide on norepinephrine response in human hypertension (Abstract). Clin. Res. 1958, 6, 230.

21. Wanko, A., and Freis, E. D. Altered vascular responsiveness following chlorothiazide or mercurial diuresis in normotensive subjects (Abstract). Circulation 1958, 18, 792.

22. Aleksandrow, D., Wysznacka, W., and Gajewski, J. Influence of chlorothiazide upon arterial responsiveness to nor-epinephrine in hypertensive subjects. New Engl. J. Med. 1959, 261, 1052.

23. Freis, E. D., Wanko, A., Schnaper, H. W., and Frohlich, E. D. Mechanism of the altered blood pressure responsiveness produced by chlorothiazide. J. clin. Invest. 1960, 39, 1277

24. Varnauskas, E., Cramer, G., Malmcrona, R., and Werkö, L. Effect of chlorothiazide on blood pressure and blood flow at rest and on exercise in patients with arterial hypertension. Clin. Sci. 1961, 20, 407 .

25. Dustan, H. P., Cumming, G. R., Corcoran, A. C., and Page, I. H. A mechanism of chlorothiazideenhanced effectiveness of antihypertensive ganglioplegic drugs. Circulation 1959, 19, 360.

26. Aleksandrow, D., Wysznacka, W., and Gajewski, J. Studies on the mechanism of the hypotensive action of chlorothiazide. New Engl. J. Med. 1959, 260, 51.

27. Conway, J., and Lauwers, P. Hemodynamic and hypotensive effects of long-term therapy with chlorothiazide. Circulation 1960, 21, 21.

28. Frohlich, E. D., Schnaper, H. W., Wilson, I. M., and Freis, E. D. Hemodynamic alterations in hypertensive patients due to chlorothiazide. New Engl. J. Med. 1960, 262, 1261. 